\title{
La valoración de lo metalingüístico a través de verbos de habla checos
}

\author{
José Alejandro CALERo DíAZ \\ Universidad de Granada (España) \\ jacalero@ugr.es
}

Recibido: Diciembre de 2011

Aceptado: Febrero de 2012

\section{Resumen}

La lengua coloquial checa presenta un grupo bastante extenso de verbos que contienen un componente valorativo (negativo) y que expresan, además, información metalingüística. Dichos verbos de habla de la lengua coloquial checa y sus equivalentes en español están integrados dentro de un dominio léxico que describe todos los tipos de maneras y actos de habla inapropiados posibles. En este artículo pretendo defender el estudio de la valoración negativa de los actos de habla, del hablante y de la actividad del habla en general. También, defiendo la posibilidad de determinar una taxonomía de lexemas que reflejan la valoración negativa de los actos de habla a través de las diferentes transgresiones o violaciones de las premisas o reglas comunicativas. Esta perspectiva nos insta a replantearnos la Teoría de los Actos de Habla.

Palabras clave: valoración (negativa), actos de habla, verbos checos, información metalingüística, colquial

\section{The Evaluation of the Metalinguistic Facts through the Speech Verbs in Czech Language}

\begin{abstract}
The colloquial Czech language shows a broad group of speech act verbs which contain a "meta-linguistic" (negative) value-judgements. As the colloquial speech act verbs in Czech as their equivalents in Spanish are integrated in a lexical domain which describes all possible inappropriate speech acts or inappropriate manners of speaking. My intention with this paper is to defend the study of the negative evaluation of the speech acts, speaker and the speech activity in general. We can determine a taxonomy of the lexemes which reflect the negative evaluation of the speech acts through the different transgressions of the communicative premises or rules. This perspective invites us to re-explain the speech act theory.
\end{abstract}

Key words: (Negative) Evaluation, Speech Act, Czech Verbs, Meta-linguistic Information, Colloquial. 


\section{Uso metalingüístico de la lengua cotidiana}

En la lengua checa venimos observando una gran cantidad de verbos que reflejan maneras de hablar/decir en checo. Éstos, a su vez, designan diferentes tipos de elementos o realidades presentes en la comunicación, es decir, hablante, mensaje, código, etc., por ejemplo: el verbo kecat hace referencia al mensaje, ya que significa "hablar sin ton ni son/decir tonterías"; el verbo šprechtit hace referencia al código, expresando "hablar alemán" o "dominar muy bien una lengua"; y los lexemas slepičit, krafat, krákorat hacen referencia a la calidad moral, ética o estética del hablante, puesto que expresan "chismear, cacarear". Debido al uso metalingüístico que se deriva de los verbos checos que reflejan la "manera de hablar" podemos afirmar que por medio de ellos logramos designar cualquier tipo de realidad lingüística y que esta designación no sólo describe las realidades o entidades presentes en el proceso comunicativo (emisor, receptor, código, etc.), sino que también hacen lo propio desde diferentes niveles, planos y saberes de la lengua (COSERIU 1992). Sirvan de ejemplo algunos de los niveles lingüísticos:

fónico: šišlat=cecear, ječet=chillar

semántico: plácat=hablar sin ton ni son/decir tonterías

A través de este tipo de lexemas son susceptibles de ser designados elementos, conceptos y unidades que, por lo general, cada corriente lingüística considera necesarios para el análisis de la lengua o para la parcela de ésta que se investigue, por ejemplo, la expresión hablar sin ton ni son-plácat refleja tanto la invalidez del plano del contenido como la invalidez de las condiciones de sinceridad, donde el primer concepto es estudiado desde varias corrientes, entre las que cabe destacar el estudio sobre las competencias lingüísticas de Coseriu y el segundo concepto se desarrolla, sobre todo, a partir de la teoría de los actos de habla.

En cierta medida el estudio de "lo metalingüístico" en la lengua cotidiana entra en contradicción con el concepto tradicional de metalingüística. Sin embargo, numerosos lingüistas vienen demandando la revisión y reconstrucción del concepto para su inclusión dentro de la función referencial y expresiva de la lengua (ŠOLTYS 1983; LOUREDA 2005; AZNÁREZ 2006; CALERO 2010).

Una dificultad añadida en el estudio de dichos lexemas es el carácter descriptivo $\mathrm{y}$, a la vez valorativo, de gran cantidad de estos verbos aunque, ya que en la lengua checa dichos lexemas pertenecen a lo que se conoce como běžná mluvená češtinacheco hablado común, registro expresivo de la lengua que oscila entre lo normativo y lo no normativo.

\section{Procedimientos ante la condición metarreferencial de los verbos de habla}

En este sentido, debemos ser extremadamente cuidadosos con el tipo de metalenguaje que vamos a emplear puesto que, algunas veces, describiremos las características propias de los lexemas en particular y en otras ocasiones describiremos características de la lengua en general. En otras palabras, debemos utilizar un metalenguaje adecuado para la descripción del uso metalingüístico del lenguaje cotidia- 
no. Algunos autores (MORTAVA 1985; MALDONADO 1991) han observado la cuestión del uso metalingüístico del lenguaje cotidiano en el discurso indirecto, circunstancia esta que nos conduce a la superposición de varios metalenguajes: el metalenguaje cotidiano (referido a la lengua desde la lengua cotidiana) y el metalenguaje científico.

Mortava Garavelli (1985: 21) compara esta condición del discurso reproducido con el juego de las cajas chinas en el que dentro de un discurso se encuentra otro discurso y así sucesivamente. Dicho de otra manera, una enunciación $E$ enuncia otra enunciación $E_{1} \mathrm{y}$, ésta a su vez, otra enunciación $E_{2}$, etc. Este hecho nos conduce a diferenciar dos hablantes: el implícito en el enunciado o predicado del acto de habla y el hablante que valora dicho acto. De esta manera, si un hablante 1 dice algo y un oyente reproduce o refiere "lo dicho", el oyente está realizando también un acto de habla, es decir, se convierte en hablante 2 haciendo un uso metalingüístico del lenguaje primario, o sea, se refiere a un discurso o enunciado, por lo general, ajeno y/o anterior.

El hablante 2 al que llamaremos hablante crítico (en adelante HC) puede referirse: a la actividad de hablar, a la realización del acto de hablar e incluso al propio hablante 1 (es decir, hablante original, en adelante $\mathrm{HO}$ ) entre otras realidades. Por ejemplo: hantýrkovat es un verbo que designa que el HO se expresa en argot, o sea, que mediante él se refleja la actividad de hablar, hecovat expresa incitar, por lo que, de alguna manera se está reflejando el comportamiento del HO con un receptor, bonznout expresa chivarse de algo, de esta manera, no sólo se refleja el comportamiento reprochable del $\mathrm{HO}$ sino la realización del acto de habla.

\section{Valoración axiológica y componente axiológico}

Siempre ha existido cierta reticencia desde la Lingüística a analizar verbos que reflejan actos de habla, cuyo contenido semántico incluye un componente valorativo, ya que éste, aunque no siempre, suele presentar un carácter negativo.

Ante esta circunstancia, observamos que existen en Lingüística diferentes perspectivas que nos pueden servir de guía para tratar esta problemática. La axioemática de FELICES $(1991$; 1992) propone en este sentido una taxonomía de los juicios de valor reflejados mediante el léxico de las lenguas y que se encuentra en consonancia con otras teorías desarrolladas desde la semántica (v. LAKOFF 1980a/1980b; WIERZBICKA 1992: 223):

ARCHIAXIOEMAS CONSTANTES:

- Positivo(+), Neutral(0), Negativo(-)

- Diversos grados (++), (- -)

ARCHIAXIOEMAS VARIABLES O CANÓNICOS (en virtud de la adecuación o transgresión de ciertas normas):

- Good1 - Bad1 = Evaluación descriptiva/genérica.

- Good2 - Bad2 = Evaluación conductual de carácter genérico.

- Good3 - Bad3 = Evaluación conductual de carácter ético. 
- Good4 - Bad4 = Evaluación pragmático-funcional y adecuacional.

- Pleasant1 - Unpleasant1

- Pleasant2 - Unpleasant2

AXIOEMAS DE GRADO:

Máximo - Alto - Mediano - Bajo

AXIOEMAS DE ESTILO:

Fásica y estrática

\section{La inclusión del componente axiológico en los verbos de habla y verba dicendi}

Basándonos en la taxonomía de los diferentes axioemas y normas expuestas por Felices Lago proponemos una taxonomía de actos de habla en la que se integre el componente axiológico. Para ello debemos exponer qué tipo de violaciones comunicativas expresan los verbos que expresan "manera de hablar/decir" en checo y sus equivalencias en español.

\subsection{Competencias lingüísticas del hablante}

La afirmación de LOUREDA (2005: 192), que introducimos a continuación, está cuestionada en gran medida por el componente axiológico incluido en el contenido semántico de la valoración de la manera de hablar/decir en checo y español, ya que, para "hablar", no es necesario significar y diríamos que ni siquiera comunicar:

El contenido común a todos los nombres de los tipos de texto es 'lo que se dice'. El significado 'lo que se dice' implica una triple determinación. La primera se refiere al emisor: el hablante es un ser humano; luego 'decir' equivale a 'emitir sonidos el hombre'. La segunda determinación viene dada por la necesidad de que lo expresado sea significativo: el significado 'lo que se dice', por tanto, no incluye los nombres de simples sonidos, como voz, grito, berrido, chillido, murmullo, runrún o rumor. La tercera y última precisión concierne al plano lingüístico: el significado 'lo que se dice' se refiere al nivel del discurso, al de lo efectivamente dicho (según Coseriu, al nivel individual del lenguaje) (La cursiva es nuestra)

Por ejemplo: el verbo checo kecat-hablar sin ton ni son designa un tipo de actividad de hablar en la que la validez del contenido proferido por el hablante se pone en cuestión y, por el contrario, bručet-refunfuñar hace referencia a un hablante que habla para sí mismo. Como podemos apreciar, ambos verbos no reflejan las premisas necesarias para la significación y la comunicación. Aunque los trabajos sobre los verbos denominados de habla, de comunicación o dicendi no se refieran de manera explícita al componente axiológico, éste se observa implícitamente en el uso metalingüístico de la lengua cotidiana, señalado por autores como AZNÁREZ (2006).

Šoltys, en la afirmación que recogemos a continuación (1983: 23), se refiere sucintamente a diversos niveles de la lengua (el diafásico y el diastrático) y a la necesidad humana de describir y juzgar la actividad de "hablar": 
Hemos buscado en la lengua corriente hablada y nos hemos planteado la pregunta de Mathesius: ‘¿Cuándo tiene el hombre la necesidad informativa de expresarse sobre el instrumento de comunicación?'. Y efectivamente a esta pregunta se responde de una forma muy sencilla: si de alguna manera o por alguna circunstancia debe dirigir su atención a la lengua. [...] Todos sabemos por experiencia que no dirigimos nuestra atención a los instrumentos que funcionan de forma segura, sin problemas, automáticamente, digamos no marcados, sino que nos referimos a aquellos instrumentos que, de alguna manera, ya sea por defecto o porque satisfacen con creces nuestra necesidad de trabajar con ellos, o sea, a los instrumentos que están en una posición marcada. Podemos presentar unas cuantas expresiones sobre la lengua en dicha posición marcada. (La cursiva es nuestra).

Eugenio COSERIU (1992: 85) observa como "los hablantes valoran el hablar en el sentido de si responde a lo que por lo regular es esperable, es decir, si es "normal". La posición marcada a la que se refiere Otakar Šoltys en su afirmación es aquella que, de alguna manera, "destaca" frente a la posición no marcada. La posición marcada se encuentra en oposición binaria con la posición no marcada, en relación al funcionamiento de la lengua. Por lo general, a pesar de lo que afirma Šoltys, dicho funcionamiento que destaca por no ser el normal está, más bien, marcado cuando es, por alguna circunstancia, errático y no cuando destaca por satisfacer sobradamente nuestras necesidades comunicativas. Así, en la lengua checa existen más expresiones que expresan mal funcionamiento de la lengua que expresiones que expresan su funcionamiento correcto.

Mal funcionamiento: šišlat-cecear, huhñat-gangosear (desde el punto de vista del plano de la expresión, la realización de la articulación); blábolit-balbucear, hablar sin sentido.

Buen funcionamiento: šprechtit-hablar bien alemán u otra lengua/ chapurrear ${ }^{1}$.

\subsection{Expresiones ininteligibles}

Searle usa los términos output e input para referirse a una serie "extensa e indefinida de condiciones" indispensables en la comunicación lingüística:

'Output' cubre las condiciones requeridas para hablar inteligiblemente e 'input' cubre las condiciones requeridas para la comprensión. Juntos incluyen cosas tales como que el hablante y el oyente conozcan cómo hablar la lengua; que ambos sean conscientes de lo que están haciendo; que el hablante no esté actuando bajo coacción o amenazas; que no tengan impedimentos físicos para la comunicación tales como sordera, afasia o laringitis; que no estén actuando en una obra de teatro o hablando en broma, etc. (SEARLE 1977: 9).

Como podemos apreciar, Searle introduce mediante los términos input/output dos premisas necesarias en la comunicación: inteligibilidad y comprensión que nos indican la existencia de dos grandes subdominios en los verbos que expresan "manera de hablar en checo": i) verbos que valoran cómo se realiza la actividad de hablar en el plano de la expresión: bručet-refunfuñar/mascullar, brblat-refunfuñar/mascullar,

\footnotetext{
${ }^{1}$ Como hemos señalado es extraño encontrar dentro del corpus verbos que expresen buen funcionamiento, o valoración positiva. En el caso del lexema mencionado habría que tener en cuenta el contexto en el que es usado, ya que puede tener tanto valor positivo como negativo. Se trata pues del uso positivo de un disfemismo.
} 
šišlat-cecear, koktat-tartamudear, drmolit-hablar a trompicones, žmolit-mascullar, etc. y ii) verbos que valoran cómo se realiza la actividad de hablar en el plano del contenido: kecat, plácat, žvanit-hablar sin ton ni son, hablar demasiado, decir tonterías. Al comparar los lexemas objeto de estudio con los conceptos presentados, observamos que los verbos que reflejan el plano de la expresión, a saber, verbos que expresan actos de locución, emisión, etc. son utilizados por el HC para valorar la manera de hablar del $\mathrm{HO}$ a partir de normas estéticas, noéticas y normas sensitivas de carácter biológico, hedónico, vital (JIMÉNEZ 1998: 287-291).

Volviendo a las condiciones input/output, advertimos que los conceptos inteligibilidad y compresión, aunque próximos al plano del contenido, no son suficientes para desde ellos poder otorgarle validez o no a dicho plano. Esto se debe a que el plano del contenido es un reflejo del uso referencial que hacemos del acto de habla, y éste no depende de la capacidad del hablante para hacerse entender (output) o comprender por el oyente (input), sino de la relación que se establece entre una expresión "lo que se dice" y un referente.

De ahí la necesidad de plantearnos la siguiente pregunta: ¿cuáles son las premisas necesarias para la validez referencial del acto de habla? Son varias pero cabe destacar la siguiente: que el contenido de "lo que se dice" sea verdadero.

\subsection{Veracidad de "lo que se dice"}

La teoría de los actos de habla nos ofrece todo un repertorio de máximas, premisas, presupuestos, etc. sin los cuales se frustrarían las intenciones comunicativas del hablante (AUSTIN 1962: capítulo II; SEARLE 1970: 60-67). A continuación observaremos cómo la veracidad de "lo que se dice" guarda relación directa con el resto de máximas conversacionales y cómo el lexema kecat niega todas las máximas expuestas por GRICE (1975: 46 y ss.). Para ello, proponemos dos tipos de acercamientos: el primero consiste en el análisis contrastado entre las desinencias procedentes del Slovník Nespisovné Češtiny (2006) con las formas léxicas recogidas por AZNÁREZ (2006) y que nos servirá para demostrar que el verbo kecat representa la violación de todas las máximas descritas por Grice. El segundo acercamiento consiste, más bien, en un acercamiento traductológico a través de los equivalentes mostrados en las traducciones de varias obras checas y españolas.

Acercamiento lexicográfico:

Máximas de cantidad

(1) Haga que su contribución sea tan informativa como sea necesario

(teniendo en cuenta los objetivos de la conversación).

(2) No haga que su contribución resulte más informativa de lo necesario.

[Hablar mucho, hablar en vano=jak dlouho bude ještě kecat?-¿cuánto tiempo se va a tirar hablando/diciendo tonterias ?2].

Máximas de cualidad

\footnotetext{
${ }^{2}$ Los equivalentes en español que aquí se introducen parten de la contrastación de significados entre los diferentes verbos del corpus extraído, así como de la constatación de los diferentes valores expresivos y semánticos del verbo en cuestión: kecat. Por lo tanto, se ha intentado establecer para cada acepción o dimensión semántica un valor expresivo igual o, en su defecto, neutral. Por ejemplo: decir sinsentidos-decir tonterías, hablar mucho y en vano-estar de cháchara. Es importante señalar que kecat muestra un objeto inherente a su acción "lo que se dice" y que dicha acción más el objeto inherente en español, generalmente, se expresan mediante un frasema: decir tonterías, estar de cháchara, etcétera.
} 
Su máxima general: trate de que su contribución sea verdadera.

(1) No diga lo que crea que es falso.

(2) No diga aquello de lo cual carezca de pruebas adecuadas.

[Hablar absurdamente, no decir totalmente la verdad, decir sinsentidos $=$ Co to kecáš?-¿Pero qué tonterías dices/hablas*?].

Máxima de relación

Vaya al grano (sea relevante).

[Hablar en vano, conversar de manera trivial, decir sinsentidos=Přestan̆ kecat nesmysly-iDeja de decir sinsentidos!].

Máximas de modo

Su máxima general: sea perspicuo.

(1) Evite ser oscuro al expresarse.

(2) Evite ser ambiguo al expresarse.

(3) Sea escueto (y evite ser innecesariamente prolijo).

(4) Proceda con orden.

[Hablar absurdamente, decir sinsentidos, hablar en vano, hablar mucho=Kecali jsme celou noc-Estuvimos de cháchara toda la noche].

Acercamiento traductológico:

"Ale brácho, přestaň kecat nesmysly.”-“Ay hermanito, cómo dices pendejadas." (Psí Lásky-Amores perros, Guillermo Arriaga, 2009)

"Nebyla však docela prosta kontroly, takže připojila otázku: Nebo kecám?”-“Pero no había perdido del todo el control, así que añadió una pregunta: ¿O estoy diciendo tonterías?" (La broma-Žert, Milan Kundera, 1994)

“čokoláda... a anální sex. Žes to nikdy nezkoušela? Nekecej.”-"el chocolate... y el sexo anal. ¿Que nunca lo has probado? No me lo creo." (Láska, zvědavost, prozac a pochybnosti-Amor, curiosidad, prozac y dudas, Lucía Etxebarria 2007)

\section{La inclusión de lo socialmente reprochable en la teoría de los actos de habla}

Los verbos que representan "actos ilocutivos o perlocutivos socialmente reprochables" en checo son muy numerosos, y la definición de "lo socialmente reprochable", obviamente, podría ser aplicable a verbos que valoran tanto la falta de veracidad de lo que se predica como la no inteligibilidad de las palabras emitidas. Sin embargo, en este apartado dedicaremos nuestra atención a los actos reprochables que hacemos al hablar, siguiendo la concepción austiniana desde la que parte toda la teoría de los actos de habla. Anteriormente hemos introducido las máximas conversacionales de GRICE (1975) para mostrar las razones por las que el plano del contenido es valorado negativamente. BACH y HARNISH (1979: 64) añaden a estas máximas otras dos más, que emplea el hablante para regir su comportamiento moral y ético: 
- politeness: the speaker (in speaking) behaves polity, that is, $S$ is not offensive, abusive, rude, vulgar.

- morality: the speaker (in speaking) behaves morally, that is, $S$ :

i. does not reveal information he ought not reveal,

ii. does not ask for information he shoudn't have,

iii. does not direct $H$ to do/tell something $H$ shoudn't do/tell,

iv. does not commit himself to do something for $\mathrm{H}$ that $\mathrm{H}$ does not want done.

La ausencia de estas máximas descritas por Bach y Harnish indica, obviamente, la transgresión del canon conductual de carácter ético (FELICES 1991). Debemos admitir, entonces, que mediante los lexemas que forman parte de este grupo valoramos tanto al hablante como al acto de habla predicado por él. Como hemos adelantado, estos lexemas presentan determinadas variaciones diafásicas que los alejan de la lengua estándar: registro coloquial, familiar, estilo vulgar, etc. Esto debe traducirse en la búsqueda de equivalentes en español con las mismas características:

bonzovat-chivarse, heftovat-comerle la olla a alguien/persuadir, hecovatpicar/lanzar pullas/incitar, kérovat-persuadir, balamutit-quedarse con alguien, mistrovat-ir de listo, drbat-chismear, etc.

La Lingüística discute la pertinencia de incluir estos verbos dentro de la teoría de los actos de habla. Recientemente, BLANCO (2008) plantea la inclusión de algunos verbos españoles, equiparables a los analizados en el presente artículo, dentro de los actos ilocutivos y del estudio de los actos de habla. Dichos verbos son considerados por el autor como actos ilocutivos hostiles y/o socialmente mal vistos. A continuación mostramos los verbos introducidos por Blanco Salgueiro y los verba dicendi analizados en nuestra investigación (CALERO 2010) que se emplean para valorar al hablante:

- acusar: bonzovat, podkecnout, prodat, štumfnout, etc.

- anular: proprcat, stirat, zmrdat, zprcat, sprdnout, etc.

- blasfemar: nadávat, murčit, paštikovat, plit, špačkovat, štumfovat, etc.

- cotillear: drbat, sjet, etc.

Blanco Salgueiro, en su artículo sobre los actos ilocutivos hostiles, evidencia algunas deficiencias epistemológicas presentadas por la teoría de los actos de habla, que se pueden resumir de la siguiente forma:

- el énfasis excesivo en los conceptos de "cortesía" y "cooperatividad";

- el énfasis excesivo en los "estados mentales del hablante";

- el énfasis excesivo en la "explicitabilidad" de los actos de habla, y no en las atribuciones de los demás, es decir, de el/los oyente/s.

Estos puntos de vista de la teoría de los actos de habla evidencian por qué se ha rechazado, sistemáticamente, analizar los verbos que reflejan actos de habla en los que el hablante o su comportamiento son valorados negativamente.

Partamos de la tercera deficiencia denunciada por Salgueiro. En la teoría de los actos de habla, como mencionamos con anterioridad, se parte de la idea de que todo acto ilocutivo debe ser explicitado mediante la $1^{\text {a }}$ persona del singular del presente del indicativo voz activa, es decir, que todo acto ilocutivo existe en virtud de su uso 
realizativo, por ejemplo: "Iré mañana"-"Prometo que iré mañana"3. De esta creencia austiniana se sirve la teoría, a modo de fórmula universal, para determinar si se trata de un acto de habla ilocutivo o no, es decir, bajo la premisa de que sean realizativos (performativos en términos austinianos). Consecuentemente, los verbos ilocutivos son sólo verbos realizativos. Este principio epistemológico ha provocado que en los estudios dedicados a los verbos que expresan actos de habla se le haya dado preferencia a aquellos verbos que habitualmente reflejan la atribución que de dichos actos haga la $1^{a}$ persona, p. ej.: yo prometo, yo ordeno, yo pido, yo pregunto, etc. Sin embargo, como señala WIERZBICKA (1987), esto no implica afirmar que la realización de los actos de habla en $1^{a}$ persona sea más común que la realización en $3^{\mathrm{a}}$ persona. Por el contrario, como defiende la misma autora, existe una gran cantidad de verbos que no suelen tener realización en $1^{\mathrm{a}}$ persona, p.ej.: nadie puede persuadir diciendo "Yo presumo (que soy el mejor)" (1987: 16).

\subsection{Atribuciones de $1^{\mathrm{a}}$ persona $v s$. atribuciones de $3^{\mathrm{a}}$ persona}

El análisis que se deriva de las atribuciones que la $1^{\mathrm{a}}$ persona hace sobre el acto de habla supone una visión internista tanto de los actos de habla como de la fuerza ilocutiva (BLANCO 2008). WIERZBICKA (1987: 14) es consciente de que "las frases mentales en $1^{\mathrm{a}}$ persona no son más comunes que las de $3^{\text {a" }}$, sin embargo, aboga por el análisis de los speech act verbs desde el punto de vista de la $1^{\mathrm{a}}$ persona, ya que son semánticamente más simples:

Speech acts exteriorize the speaker's mental acts and metal state (his or her 'I want', 'I feel', 'I think', and so on). It is a perspective, I think, to analyse the meaning of speech acts in third person perspective, if it inherently involves, a simpler first person perspective (WIERZBICKA 1987: 14).

Según la autora, esta visión no está reñida con el análisis de la valoración externa o atribución de la $3^{a}$ persona a los actos de habla ajenos, dado que:

When we perform speech acts, we express, directly, first person attitudes. When we interpret other people's speech acts, we attribute to them, indirectly, certain first person attitudes. The first mode -direct expression-is inherently simpler semantically than the second mode (attribution)" (WIERZBICKA 1987: 16). (La cursiva es nuestra).

Desde la Gramática Funcional de Dik se ha observado, también, la falta de realizativos explícitos frente a la gran cantidad de realizativos primarios: "[...] explicit performative expressions are extremely rare" (DIK 1997: 233). La propia Gramática Funcional observa que existen diferencias en la interpretación de la ilocución a tener en cuenta (DIK 1997: 231):

- the illocution-as-intended-by-S

- the illocution-as-coded-in-the-expression

- the illocution-as-interpreted-by-A

$$
\begin{aligned}
& \mathrm{Ill}_{\mathrm{S}} \\
& \mathrm{Ill}_{\mathrm{E}} \\
& \mathrm{Ill}_{\mathrm{A}}
\end{aligned}
$$

\footnotetext{
${ }^{3}$ La primera oración se denomina realizativa primaria o realizativos indirectos, la segunda es una realizativa explicita.
} 


\subsection{La fuerza ilocutiva inadecuada}

A través de los criterios manejados, advertimos la necesidad de abordar la dicotomía existente entre la fuerza pretendida y la fuerza efectiva como problema de estrategia del hablante (HO). En este sentido, Fraser acuñó el concepto de mitigation que se define como la estrategia mediante la cual se suaviza o reduce la fuerza de un acto ilocutivo cuyos efectos pueden ser no bienvenidos-unwelcome por el destinatario (FRASER 1980: 342). Gracias a esta concepción, podemos observar que significaciones como reprender-stírat, hubovat o decir tacos-nadávat reflejan que en el acto de habla no se han adoptado las medidas oportunas (de mitigación de la fuerza ilocutiva) para poder ser, dicho acto, considerado como adecuado.

Como se puede observar, en el subdominio léxico de "actos ilocutivos socialmente reprochables", existe una gran cantidad de unidades léxicas que refleja la inadecuada mitigación de la fuerza ilocutiva en checo y español:

Hubovat: Regañar, reprender, reñir.

Proprcat: Echar la bulla, poner a caldo.

Zmrdat: Echar la bulla, poner a caldo, meter/dar caña a alguien.

Hecovat: Lanzarle pullas a alguien, coñearse de alguien

Držkovat: Ponerse borde/chulo.

Jebat do koho: dar la tabarra/el coñazo, fastidiar (continuamente/siempre) con algo.

Uvrtat: taladrar a alguien, dar la tabarra.

\section{Conclusiones}

Podemos concluir afirmando que existe una gran cantidad de formas léxicas en las lenguas checa y española cuyo principal rasgo semántico-pragmático consiste en aportar información sobre los "hechos del lenguaje" y que dicha información, por lo tanto, es susceptible de ser considerada como "metalingüística". Además, observamos que las diferentes unidades léxicas que reflejan tal información contienen una nítida carga valorativa (negativa) en checo y en español, lo cual se refleja en su alto índice coloquial. A través de la observación de las violaciones y transgresiones comunicativas acometidas en el acto de habla se puede establecer una taxonomía de la "valoración negativa de lo metalingüístico" y delimitar nuestro corpus en tres dimensiones semánticas: i) valoración del plano de la expresión: huhñat-gangosear, bručet-refunfuñar, brblat-refunfuñar, blábolit-balbucear; ii) valoración del plano del contenido: kecat/plácat/blábolit-hablar sin ton ni son/decir tonterías y iii) actos ilocutivos socialmente reprochables: drbat-chismear, hecovat-lanzar pullas. Esto nos lleva a concluir que dichas significaciones se caracterizan por expresarse a través de léxico expresivo, coloquial y vulgar en ambas lenguas, siendo típico en español el uso de perífrasis, frasemas, partes de frasemas, complementos explicativos, etc. frente al uso preferente del verbo en checo. 


\section{Referencias bibliográficas}

AUSTIN, J. L. (1962): How to Do Things with Words, Oxford University Press, Oxford.

AZNÁREZ MAULEÓN, M. (2006): Fraseología metalingüistica con verbos de lengua en español actual, Peter Lang, Frankfurt am Main.

BACH, K. y R. M. HARNISH (1979): Linguistic Communication and Speech Act, The MIT Press, Cambridge.

BLANCO SALGUEIRO, A. (2008): "Cómo hacer cosas malas con palabras: actos ilocucionarios hostiles y los fundamentos de la teoría de los actos de habla", CRÍTICA, Revista hispanoamericana de Filosofia, Vol. 4, N 118, pp. 3-27.

CALERO DÍAZ, J. A. (2010): Análisis del dominio léxico de los verbos que expresan manera de hablar y su componente valorativo en la lengua checa, Tesis doctoral, Tesis inédita, Universidad de Granada, Granada.

CHARLESTON, B. (1960): Studies on the Emotional and Affective Means of Expressions in Modern English, Schweizer Anglistiche Arbeiten, Francke Verlag, Bern.

COSERIU, E. (1981): Lecciones de lingüistica general, Gredos, Madrid [Versión original: Lezioni di Lingüistica Generale, Boringhieri, Torino, 1973.]

COSERIU, E. (1992): Competencia lingüistica, Gredos, Madrid. [Versión original: Sprachkompetenz. Grungzüge der Theorie des Sprechens, A. Francke Verlag GmbH, Tübingen, 1988.]

DANEŠ, F. (1973): “Verba dicendi a výpovědní funkce”, en Studia Slavica Pragensia, Praha, pp. $115-124$.

DIK, S. C. (1997): The Theory of Functional Grammar, Part 2: Complex and Derivated Constructions, Mouton de Gruiter, New York.

FELICES LAGO, Á. M. (1991): El componente axiológico en el lenguaje. Su configuración en los adjetivos que expresan emociones y conducta en la lengua inglesa, Tesis doctoral, Edición en microfichas. Universidad de Granada, Granada.

FELICES LAGO, Á. M. (1992): "Recensión de las contribuciones más valiosas para la axioemática en la lingüística moderna", Revista española de lingüística aplicada.

FRASER, B. (1980): “Conversational mitigation”, Journal of Pragmatics 4, pp. 341-350.

GECKELER, H. (1976): Semántica estructural y teoría del campo léxico, Gredos, Madrid. [Trad. de la $2^{\mathrm{a}}$ edición original: Strukturelle Semantik und Wortfeldtheorie, en Wilhelm Fink Verlag, München, 1971].

GRICE, H. P. (1975): "Logic and Conversation", en Cole y Morgan, Syntax and Semantics III, Academic Press, New York, pp. 41-58.

HARE, R. M. (1968): The Language of Morals, Oxford University Press, New York.

HIRSCHOVÁ, M. (1988): Česká verba dicendi v performativním užití, (přispěvek ke zkoumání komunikativních funkcí výpovédí), Univerzita Palackého, Olomouc.

JIMÉNEZ HURTADO, C. (1998): "Prototipos pragmáticos en el lexicón (La inclusión de la pragmática en el concepto de campo léxico)", en G. Wotjak (coord.), Teoría del campo y semántica léxica, Peter Lang, Frankfurt am Main, pp. 275-302.

LAKOFF, G. y M. JOHNSON (1980): Metaphors We Live By, The University of Chicago Press, Chicago.

LAKOFF, G. y M. JOHNSON (1980b): “Conceptual Metaphor in Everyday Language”, The Journal of Philosophy, Vol. 77, №. 8, pp. 453-486.

LOUREDA LAMAS, Ó. (2005): "La estructura del campo léxico 'lo que se dice' en el español actual" en Casado Velarde et al. (eds.), Estudios sobre lo metalingüístico (en espanol), Peter Lang, Frankfurt am Main, pp. 191-210.

MARTIN MINGORANCE, L. (1987): "Classematics in a Functional-Lexematic Grammar 
of English", Actas del X Congreso Nacional de la AEDEAN, Zaragoza, pp. 377-382.

MARTIN MINGORANCE, L. (1998): El Modelo Lexemático-Funcional. El legado lingüístico de Leocadio Martín Mingorance, ed. Amalia Marín Rubiales, Universidad de Granada, Granada.

MORTAVA GARAVELLI, B. (1985): "Per una tipologia del discorso raportato", La parola d'altri. Prospettive di analisi del discorso, Sellevio Editore, Palermo, pp. 17-50.

SEARLE, J. R. (1970): Speech Acts: An Essay in the Philosophy of Language, Cambridge University Press, Cambridge.

SEARLE, J. R. (1977): “¿Qué es un acto de habla?”, Revista Teorema, http://www.upv.es/.

ŠOLTYS, O. (1983): “Verba dicendi a metajazyková informace”, Linguistica VIII, Československá Akademie Věd, Ústav pro jazyk český, Praha, pp.155-124.

WIERZBICKA, A. (1987): English Speech Act Verbs: A Semantic Dictionary, Academic Press, Australia.

WIERZBICKA, A. (1992): Semantics, Culture and Cognition: Universal Human Concepts in Culture-Specific Configurations, Oxford University Press, New York. 